\title{
与北大西洋接壤的北极海冰和年际气候变化
}

\author{
武炳义 黄荣辉 高登义 \\ (中国科学院大气物理研究所, 北京 100080. Email: wby@mail.iap.ac.cn)
}

摘要 冬季与北大西洋接壤的北极海冰面积变化与北大西洋区域气候变化有着非常密切的联系. 当冬季北大西洋涛动指数处于异常偏高(低)时期, 冰岛低涡加深(减弱)位置偏北(南), 北大西洋副 热带高压也偏强(弱), 并且位置也偏北(南), 导致中纬度纬向西风偏强(弱), 受其影响中纬度北大 西洋海温升高(降低), 因而增强(减弱)暖洋流向高纬度区域输送, 流入巴伦支海的北大西洋海水增 多(减少), 致使巴伦支海南部混合层水温偏高(偏低); 同时, 大气温度场分布也表明, 欧洲北部及 其相邻的北极区域增暖(变冷)以及巴芬湾、戴维斯海峡附近区域气温降低(升高), 致使喀拉海、 巴伦支海海冰减少(增多)以及巴芬湾、戴维斯海峡海冰增加(减少).

关键词 冬季 北大西洋涛动 海冰面积

北大西洋区域是影响气候变化的关键区之一. 这里有携带巨大热量向北输送的最大暖洋 流—墨西哥湾流; 有北大西洋深水环流以及影响长期气候变化的温盐环流异常一一的盐 度异常 ${ }^{[1]}$, 有人认为北大西洋海水大的盐度异常事件是仅次于 ENSO 事件的第二大海洋异常 信号 ${ }^{[2]}$. 它的变化对深水环流的形成以及对长期气候变化的影响正日益引起人们的关注.

此外, 这里有全年都存在的北大西洋涛动(NAO), 除了南方涛动外, 北大西洋涛动是气候 年际变化的一个主要源地 ${ }^{[3]}$. 它与跨越大西洋进入欧洲的表面风场变化有比较密切的关系 ${ }^{[4]}$. 其变化可以解释北大西洋海平面气压场总方差的 $1 / 3$ 以上 ${ }^{[5]}$, 并且, 它对北半球气温变化有最 大的贡献 ${ }^{[6]}$. 因此, 研究并了解北大西洋气候变化对于理解北半球乃至全球的气候变化是大有 益处的.

而北极海冰, 尤其是与北大西洋接壤的格陵兰海、喀拉海、巴伦支海、巴芬湾和戴维斯 海峡海冰变化也受到人们的关注. 在这些海区, 海冰面积存在明显的年际变化和清晰的年代 际变化趋势[7]. 本文中, 我们主要讨论喀拉海、巴伦支海、巴芬湾和戴维斯海峡海冰变化与年 际气候变化的联系.

\section{1 数据资料和北极海冰的区域划分}

本文用到的海冰资料是由美国 Illinois 大学 Walsh 教授提供的网格点海冰密集度资料 ${ }^{[8]}$. 北半球 1946 1989 年月平均海平面气压资料是极射赤面投影的八边形网格点资料, 这里用 16 点 Bessel 插值方法将其内插到 $5 \times 5$ 的网格上. 1958 1996 年月平均海平面气压、850 hPa 大气 温度取自 NCEP 再分析资料集, 本文还用到 1950 1992 年 292 呕域海温月平均资料以及 1951 1990 年西太平洋副热带高压面积和强度指数, 1970 1994 年月平均流入巴伦支海的平均海 水流量 $\left(\times 10^{6} \mathrm{~m}^{3} / \mathrm{s}\right)$ 经 Fugl фya-Bear 岛剖面以及巴伦支海南部大陆架 Kolar(3030' E)处 0 200 m 海水温度(取自文献[9]).

首先, 以海区来划分北极海冰, 所划分的冰区如图 1 所示. 本文主要讨论与北大西洋接 壤的北极海冰变化, 即喀拉海、巴伦支海( $82 \mathrm{~N}$ 以南, 20 100至)、巴芬湾和戴维斯海峡 $(80 \mathrm{~N}$ 以 南, 45 80\%)海冰变化. 

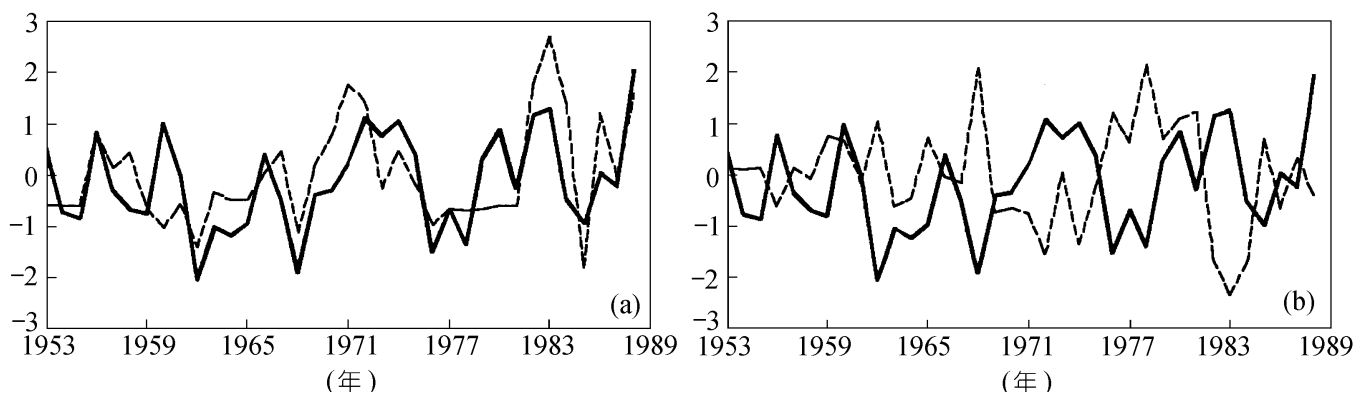

图 1

(a) 冬季北大西洋涛动指数(实线)与同时期巴芬湾、戴维斯海峡海冰面积指数(虚线)变化曲线, (b) 冬季北大西 洋涛动指数(实线)与海冰面积指数之差(虚线)的年际变化. 所有的数据均经过标准化处理

\section{2 结果分析}

在本文中, 北大西洋涛动指数定义为: 标准化的两点海平面气压 $(P(40 \mathrm{~N}, 10 \mathrm{~W})$ 与 $P(65 \mathrm{~N}$, $25 \mathrm{~W})$ )之差, 这种定义方法与 Hurrell ${ }^{[4]}$ 的定义非常相似, 他用葡萄牙 Lisbon $(38.8 \mathrm{~N}, 9.1 \mathrm{~W})$ 与冰 岛 Stykkisholmur $(65.1 \mathrm{~N}, 22.7 \mathrm{~W})$ 的海平面气压之差来表示.

冬季(12 2 月)北大西洋涛动指数(实线)与同时期巴芬湾、戴维斯海峡海冰面积指数(虚线) 年际变化曲线见图 1(a), 由图中可见, 北大西洋涛动指数存在显著的年际变化现象, 从长期变 化趋势来看, 从 20 世纪 40 年代后期到 60 年代初期, 北大西洋涛动一直在减弱; 20 世纪 60 年代中期以后逐渐变强, 并且变化幅度加大, 尤其是 20 世纪 60 年代末期以后还表现出年代 际变化趋势.

图 1(a)中显示, 冬季北大西洋涛动指数与同时期巴芬湾、戴维斯海峡海冰面积变化存在很 好的对应关系. 图 1(a)中两条曲线所代表的时间序列的相关系数高达 0.61 , 远超过 0.01 统计 显著性水平. 已有的研究表明 ${ }^{[10]}$, 冬季巴伦支海、喀拉海海冰面积变化与巴芬湾、戴维斯海 峡海冰变化呈现相反的变化趋势, 说明这两个海区海冰变化也存在类似 “跷跷板” 式的变化 关系. 为了综合反映这两个冷源之间的反向变化, 本文定义冬季巴伦支海、喀拉海与巴芬湾、 戴维斯海峡海冰面积之差来表征这两个冷源之间的变化, 其随时间演变以及与北大西洋涛动 指数的关系如图 1(b)所示. 在该图中, 海冰面积之差与北大西洋涛动指数呈现反向变化, 两者 之间相关系数为 -0.57 (超过 0.01 统计显著性水平). 由此可见, 冬季北大西洋涛动变化与北极 海冰变化存在非常密切的关系.

为了进一步分析冬季北大西洋涛动变化影响北极海冰的可能机理, 我们进行了以下分析. 首先, 从冬季 NAO 指数的时间序列(1953/1954 1988/1989 冬季, 选择这个时段是为了与海冰资 料保持一致)中分别选出前 5 个指数为最大和最小的冬季: NAO 指数最大的冬季依次是 $1988 / 1989,1982 / 1983,1983 / 1984,1972 / 1973,1974 / 1975$; 指数最小的冬季有 1962/1963, 1968/1969, 1976/1977, 1978/1979, 1964/1965. 而后, 依据选出的冬季对海平面气压、850 hPa 温 度以及北大西洋海表温度进行合成分析.

(1) NAO 指数异常偏高时期. 图 2(a)是对应 NAO 指数为正异常时的海平面气压合成分 析以及相应的地转风场. 该图显示, 冰岛低涡明显偏深, 位置偏向东北方向, 同时, 副热带高 
压也偏强、偏北. 在冰岛低涡与副热带 高压之间西风气流显著增强, 这种强西 风气流可以向东延伸到欧洲大陆北部. 在喀拉海、巴伦支海海区出现偏西南风 气流; 同时, 由于冰岛低浴偏强且位置偏 北, 致使从高纬度南下的冷空气在很高 的纬度就向西穿越格陵兰, 并与来自加 拿大北部的气流汇合, 随后向东南方向 流经巴芬湾、戴维斯海峡, 高纬度地区 冷空气的如此配置必然对冬季巴芬湾、 戴维斯海峡海冰偏多有利.

$\mathrm{NAO}$ 高指数冬季 $850 \mathrm{hPa}$ 气温的累 积距平分布如图 2(b)所示, $45 \mathrm{~N}$ 以北的欧 亚大陆都是正温度距平, 其中, 尤其以冬 季西伯利亚高压北部以及欧洲西北部气 温增暖更为显著, 在喀拉海、巴伦支海 海区也是正距平; 而加拿大纽芬兰北 部、冰岛以西区域是负温度距平, 负距 平中心正好位于巴芬湾、戴维斯海峡. 温 度累积距平分布说明冬季 NAO 高指数时 期易使喀拉海、巴伦支海海冰偏少, 而 使巴芬湾、戴维斯海峡海冰偏多.

从冬季北大西洋海表温度累积距平 的分布来看(图 2(c)), 格陵兰南部、拉布 拉多海以及戴维斯海峡部分海域海表温 度都是负距平, 表明这些海区海温偏低, 对海冰增多有利. 从该图中还可以看到:
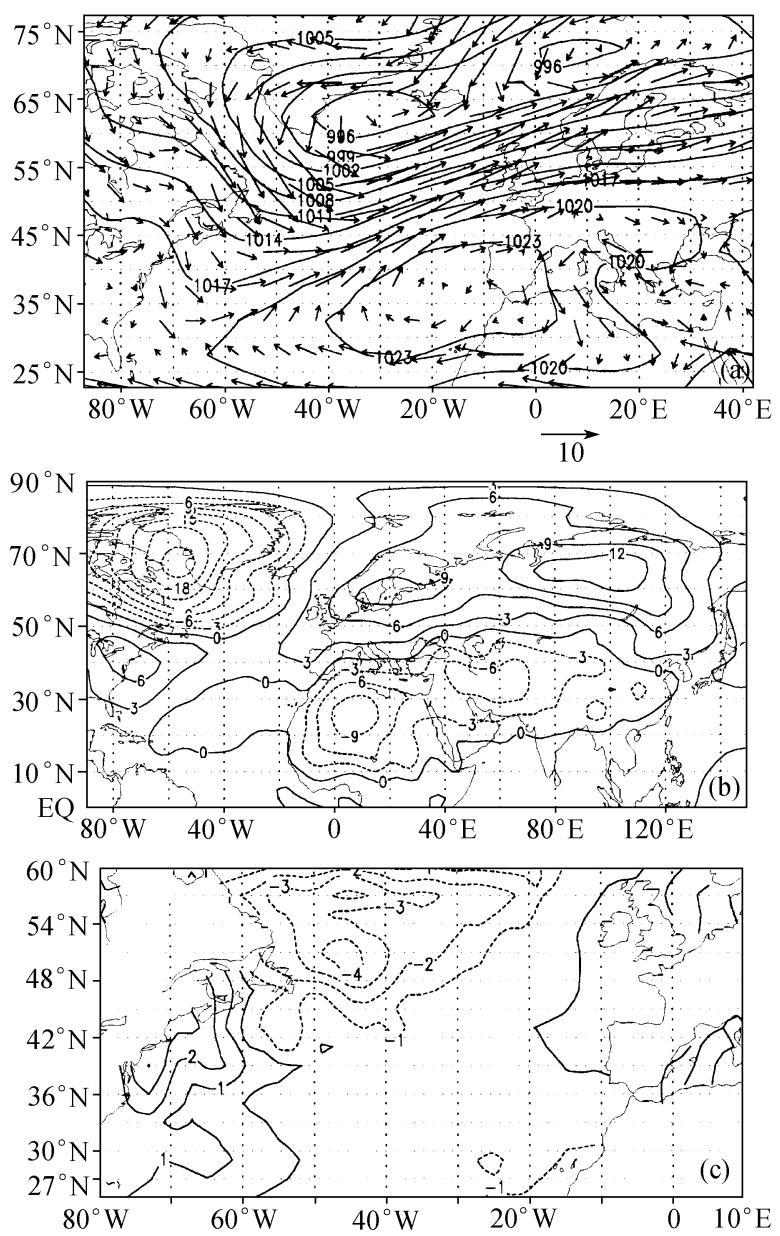

图 2

(a) 冬季 NAO 指数为正异常时期的海平面气压合成分析以及相 应的地转风场, (b) 冬季 NAO 指数异常偏高时期 $850 \mathrm{hPa}$ 气温 的累积距平分布, (c) 冬季 NAO 指数异常偏高时期海表温度的累 积距平分布

存在一个南西西 北东东走向的带状但不连续的正海温距平区, 其中, $20 \%$ 以东 $45 \sim 60 \mathrm{~N}$ 海域 正好对应海平面气压场中冰岛低压与副热带高压之间的过渡带, 受大气风场的强迫, 必然有 利于暖洋流向高纬度地区输送热量.

(2) NAO 指数异常偏低时期. 冬季 NAO 指数异常偏低时期, 如图 3(a) 所示, 冰岛低压减 弱, 并且位置偏西南, 低压中心位于拉布拉多海附近, 同时, 副热带高压也偏弱偏南, 致使北 大西洋中纬度海域西风与信风均减弱. 与 NAO 高指数时期相比, 冬季戴维斯海峡以及拉布拉 多海区北风明显减弱, 甚至出现偏南风, 来自加拿大北极地区的冷空气沿着北美洲大陆的东 南部南下, 这种形式分布必然有利于巴芬湾、戴维斯海峡海冰减少. 此时, $850 \mathrm{hPa}$ 温度场累 积距平分布与 NAO 指数异常偏高时期的正相反(图 3(b)), 45 N 以北的欧亚大陆以及北极地区 都是负温度距平, 降温最明显的区域仍然在西伯利亚高压的北部以及欧洲西北部; 而加拿大 东北部、巴芬湾、戴维斯海峡和拉布拉多海以及整个格陵兰都是气温的正距平区, 并且, 正 
距平中心也是位于巴芬湾、戴维斯海峡 附近. $850 \mathrm{hPa}$ 温度场异常分布也将使 喀拉海、巴伦支海海冰增多, 同时也导 致巴芬湾、戴维斯海峡海冰减少. 此外, 对照图 2 还可以看到, 对应 NAO 指数两 种极端异常, 在欧亚大陆以及北部非洲 大陆上, $850 \mathrm{hPa}$ 温度场异常分布完全相 反, 在这些区域, 以 $45 \mathrm{~N}$ 为分界线南北 气温距平分布也完全相反, 尤其在 20W 20E 之间气温变化的 “跷跷板” 结构非常清晰. 从海表温度的距平分布 来看(图 3(c)), 55 61 $\mathrm{N}$ 之间都是海温正 距平, 其中以格陵兰南部、加拿大纽芬 兰东北部的拉布拉多海区增温最明显; 而 40 50N 之间基本上是负距平, 与海 平面气压图对照不难看到(图 3(a)), 55N 以北海区的海温正距平主要是由偏南风 造成的, 在戴维斯海峡以及格陵兰南部 海区出现东南风, 由风驱动的海水平流 使该海区附近冷海水上翻减弱. 而海表 温度为负距平的海域则与来自加拿大以 及美国东南部的冷空气相对应. 海洋一 方面通过损失热量而降温, 同时, 由风 场驱动的上层海洋平流导致北美洲东部 的冷海水上翻, 这两个方面作用都导致 该海区海温降低.
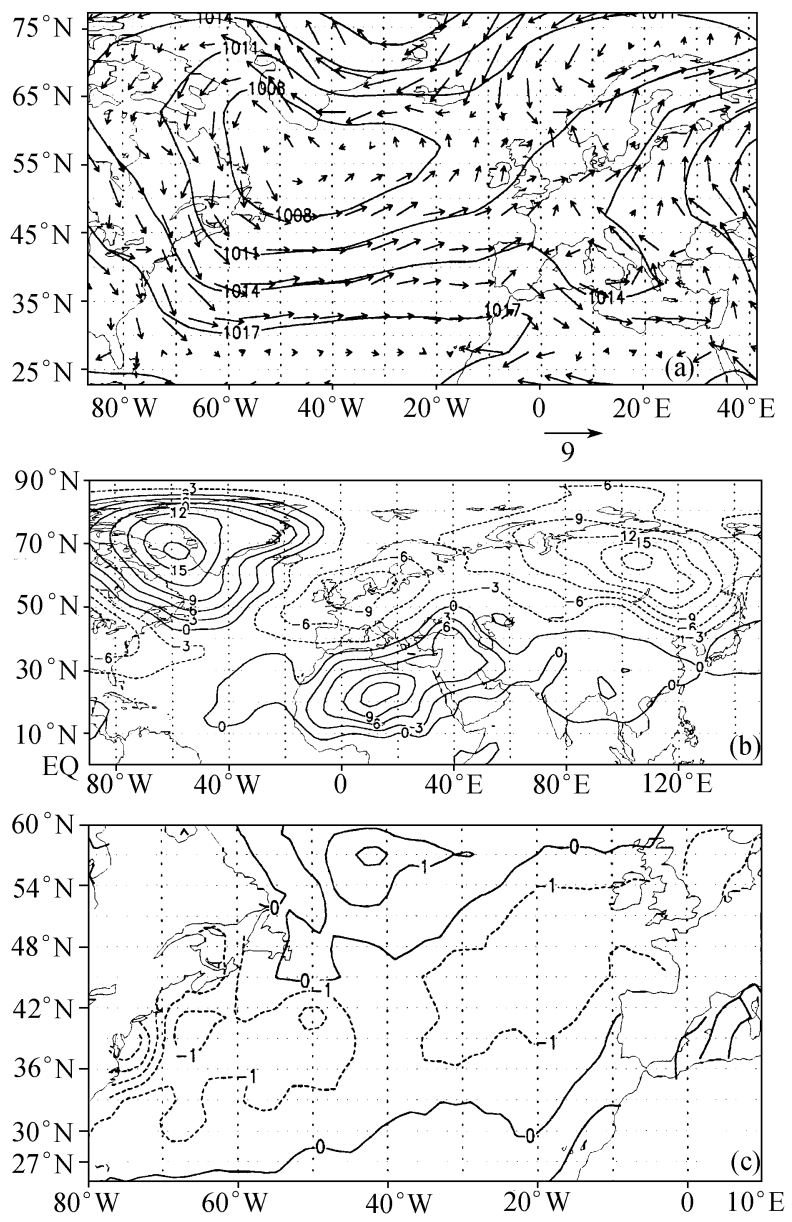

图 3

(a) 冬季 NAO 指数为负异常时期的海平面气压合成分析以及相 应的地转风场, (b) 冬季 $\mathrm{NAO}$ 指数异常偏低时期 $850 \mathrm{hPa}$ 气温 的累积距平分布, (c)冬季 NAO 指数异常偏低时期海表温度的累 积距平分布

前面提到, 受大气风场强迫, 必然

有利于暖洋流向高纬度(北极)区域输送热量, 其结果是导致高纬度海区海温升高. 冬季流入巴伦 支海的平均海水流量与其南部 0 200 $\mathrm{m}$ 平均海水温度存在非常好的关系, 如图 4(a)所示. 流入 的海水量大则混合层海温明显偏高 $(r=0.74)$, 而冬季 NAO 指数与海水流量以及混合层平均海 水温度的关系也非常密切, 相关系数分别达到 0.51 (超过 0.02 统计显著性水平)和 0.71 (超过 0.001 统计显著性水平), 如图 4(b)所示. 说明冬季 NAO 指数偏高则流入巴伦支海的海水量大, 因而该海区海温偏高. 而海温变化决定了冬季巴伦支海、喀拉海海冰面积的大小, 图 4(b)中 海水温度与海冰面积年际变化明显是反向变化关系 $(r=-0.69$, 超过 0.001 统计显著性水平).

此外, 研究发现, 春季(4 6 月平均)喀拉海、巴伦支海海冰面积变化与次年西太平洋副热 带高压的面积与强度有密切的关系, 尤其是 20 世纪 60 年代末期以后这种关系更为密切. 当 然, 也有一些年份对应关系不好, 如 20 世纪 50 年代初期和 60 年代中期. 海冰面积指数与次 年 4 6 月、5 7 月(图略)以及 6 8 月(图 4(c))西太平洋副热带高压面积(强度)指数的相关系数 
依次为 $0.45(0.41), 0.44(0.41), 0.42(0.39)$ $\left(|R|_{0.05}=0.33,|R|_{0.01}=0.42\right)$. 这说明当年 $4 \sim 6$ 月海冰偏多, 则次年由春季到夏季 西太平洋副热带高压范围偏大、强度偏 强, 这对于提前预测东亚春夏季气候变 化是很有意义的, 这一点与本文作者在 前文 ${ }^{[7]}$ 中得到的结论是完全一致的, 即 冬季喀拉海、巴伦支海海冰面积变化 超前春、夏季西太平洋副热带高压变 化 1 年.

\section{3 结论}

通过分析研究发现, 冬季与北大西 洋接壤的北极海冰面积变化与北大西 洋区域气候变化有着非常密切的联系. 当冬季北大西洋涛动指数处于异常偏 高(低)时期, 冰岛低涡加深(减弱)位置 偏北, 北大西洋副热带高压也偏强(弱), 并且位置也偏北(南), 导致中纬度纬向 西风偏强(弱), 受其影响中纬度北大西 洋海温升高(降低), 因而增强(减弱)暖 洋流向高纬度区域输送, 流入巴伦支海 的北大西洋海水增多(减少), 致使巴伦 支海南部混合层水温偏高(偏低); 同时, 大气温度场分布也表明, 欧洲北部及其 相邻的北极区域增暖(变冷)以及巴芬 湾、戴维斯海峡附近区域气温降低(升 高), 致使喀拉海、巴伦支海海冰减少(增 多)以及巴芬湾、戴维斯海峡海冰增加 (减少). 此外, 春季(4 6 月)喀拉海、巴伦支海海冰面积年际变化与次年春、夏季西太平洋副 热带高压变化存在很好的一致性.

致谢 本工作为国家自然科学基金资助项目(批准号: 49905003).

\section{参考 文 献}

1 Dickson R R, Mencke J, Malmberg S A, et al. The "Great Salinity Anomaly" in the northern North Atlantic, $1968 \sim 1982$. Prog Oceanogr, 1988, 20: 103 151

2 Mysak L A, Manak D K, Marsden R F. Sea-ice anomalies observed in the Greenland and Labrador Seas during 1901 1984 and their relation to an interdecadal Arctic climate cycle. Climate Dynamics, 1990, 5: 111 133

3 Hurrell J W, Van Loon H. Decadal variations in climate association with the North Atlantic Oscillation. Climatic Change, 
1997, 36: 301 326

4 Hurrell J W. Decadal trends in the North Atlantic Oscillation: Regional temperatures and precipitation. Science, 1995, 269: 676 679

5 Barnston A G, Livezey R E. Classification, seasonality, and persistence of low — frequency atmospheric circulation patterns. Mon Wea Rev, 1987, 115: 1083 1126

6 Hurrell J W. Influence of variations in extratropical wintertime teleconnections on Northern Hemisphere temperature. Geophys Res Lett, 1996, 23: 665 668

7 Gao D Y, Wu B Y. A preliminary study on decadal oscillation and its oscillation source of sea-ice-air system in the Northern Hemisphere. Polar Meteorology and Glaciology, 1998, 12: 68 78

8 武炳义, 高登义, 黄荣辉. 冬季格陵兰海、喀拉海和巴伦支海海冰年季变化与 ENSO 事件. 科学通报, 1997, 42(18): 1979 1981

9 Grotefendt K, Logemann K, Quadfasel D, et al. Is the Arctic Ocean warming? Journal of Geophysical Research, 1998, 103: 27679 27687

10 Parkinson C J, Cavalieri D J. Arctic sea ice 1973 1987: Seasonal, regional and interannual variability. J Geophys Res, 1989, 94(C10): 14499 14523

(2000-03-02 收稿, 2000-06-06 收修改稿) 